\title{
MutS Homolog 6 Measurement
}

National Cancer Institute

\section{Source}

National Cancer Institute. MutS Homolog 6 Measurement. NCI Thesaurus. Code C139096.

The determination of the amount of MutS homolog 6 present in a sample. 